\title{
Interpretation of Taierhchuang's Social Psychological Culture from the Village Name of Natural Village
}

\author{
Zhao Caihui \\ Zaozhuang College \\ Zaozhuang, Shandong \\ 277160
}

\begin{abstract}
Absrtact-This article takes Taierhchuang natural village name as the research object to explore and analyze the social psychological culture it reflects. By collecting materials in Taierhchuang Natural Village on the spot, this paper traces the origin of natural village names, analyzes them one by one, and summarizes and classifies them. It is concluded that the name of Taierhchuang natural village reflects the socio-psychological culture of this area, which attaches importance to religious belief, clan concept, orientation pattern and pursuit of a better life.
\end{abstract}

Keywords-Taierhchuang; Natural villages; Village name; Socio-psychological culture

\section{INTRODUCTION}

Infringement of intellectual property rights is an illegal factual conduct, which targets the exclusive right of the owner of intellectual products and differs from the ordinary torts. Geographical names of different categories and levels reflect the social life characteristics of different regions.It is a social phenomenon that arises with the emergence of human society and evolves with the development of human society. Because of its relative stability, place names can truly reflect a region's social mentality such as ideology, psychological characteristics, religious beliefs and aesthetic views. Therefore, we can study a region's socio-psychological culture through the clues provided by place names. As an important part of place names, village names are also an important carrier of social psychological and cultural heritage and have very important cultural values [1-2]. This article will explore and analyze the socio-psychological culture of Taierhchuang area through the name of Taierhchuang natural village.

Taierhchuang is located in the southernmost part of Zaozhuang City, Shandong Province, next to the Beijing Hangzhou Grand Canal, which is a pearl beside the canal. It is " the only remaining legacy village of the Beijing Hangzhou Canal" and the title of " No.1 Village in the World" written by Ganlong is still resounding today. Taierhchuang is a place with a long history and strong cultural background, and naturally has formed a specific social psychological and cultural heritage to this day [3-4].

[Author's Brief Introduction] Zhao Caihui ( 1983 - ), female, born in Zaozhuang, Shandong Province, Zaozhuang College, lecturer and master's degree, mainly engaged in the study of Chinese language and script.

\section{ATTACH IMPORTANCE TO THE SOCIO-PSYCHOLOGICAL CULTURE OF RELIGIOUS BELIEF}

The important geographical position and prosperous economy have brought immigrants from all over the world to Taierhchuang and also brought different cultural beliefs. Taierhchuang holds the culture of the North and South Canal with her means of the Grand Canal. This inclusiveness is evident in religious beliefs. Besides local folk religions, there are also Buddhism, Taoism, Islam, Protestantism and Catholicism in Taierhchuang. These religions form a rich religious pattern in Taierhchuang and all religions live together in harmony and develop together for a long time. Religious beliefs are closely related to secular life, and Taierhchuang's temples also have an impact on the naming of its villages. In the investigation of Taierhchuang's natural village names, some village names are found to be true portrayals of local people's religious beliefs [5-6].

The folk call Taierhchuang "Buddha City", although they do not know the source, it is an indisputable fact that Buddhism is flourishing in southern Shandong where Taierhchuang is located, Buddhist temples are everywhere, incense is flourishing, and there are many believers. The ancient city of Taierhchuang covers an area of only 2 square kilometers, but there are more than a dozen Buddhist monasteries that can be traced. Villagers often use Buddhist temples to name the village, such as the " big temple" because it was built next to Pilu 'an, which is commonly known as the big temple. "Former Stone Buddha" and " Later Stone Buddha" were built here in the Tang Dynasty, with three stone statues in the temple, two villages near the temple, the former Stone Buddha Temple in the south village, the latter Stone Buddha Temple in the north village, and later referred to as the former Stone Buddha and the latter Stone Buddha.

Zaozhuang's Taoist activity sites have existed since the Eastern Han Dynasty, and there are more than a dozen Taoist temples recorded in Taierhchuang alone. In Taierhchuang, the name of the natural village named after the Taoist temple includes " the former Hongmiao" and " the latter Hongmiao" because a Tianqi temple was built in the east of the village. The village was named Hongmiao and later the village was divided into two parts. "Yang 
Temple" has a jade emperor temple in the east of the village. The temple owner is named Yang, and the village is named after the temple. Some water-related immortals among Taoist immortals occupy an important position in Taierhchuang people's hearts. The history of Taierhchuang cannot be separated from the canal, and the water nourishes Taierhchuang's spiritual culture. Taierhchuang people rely on water, revere water and worship water, and then worship water-related gods. For example, the boat people in Taierhchuang worship the dragon king every year in the form of big worship, small worship, daily worship, votive worship and disaster avoidance worship, and hold a talk ceremony every year on February 2 to worship river gods. Today, there is also a traditional custom of worshiping river gods on February 2 on both sides of the ancient canal in Taierhchuang. This is also reflected in the village name, such as " East Dragon King Temple" and "West Dragon King Temple" which were divided into east and west parts in 1963 because the village was built at the Dragon King Temple. The " Ding Temple" was named after Ding officials who settled in the village and built the temple of the river during their tour of the canal.

\section{ATTACH IMPORTANCE TO THE SOCIAL PSYCHOLOGICAL CULTURE OF CLAN CONCEPT}

Clan system plays an important role in the history of the Chinese nation. For a long time, clans have tightly united the small and fragile individual life. Whether it is a high-level ruler or a lower-level civilian, they consciously or unconsciously follow the clan system and have become a unique social form in Chinese society. This feature is evident in the rural areas where the self-sufficient small-scale peasant economy predominates. The closed living environment and backward economic conditions make people of the same clan live together to form a fixed living environment, and then form a stable social system, multiply, pass on from generation to generation, and evolve into a village. This feature is reflected in the village name, which is mainly represented by the surname village name.

In the investigation of Taierhchuang's natural village names, it was found that the surname village names account for $58 \%$ of the total number of Taierhchuang's natural village names and have an absolute advantage. For example, there are many legends about the origin of the place name " Taierhchuang", and there are "surnames" to be considered. According to records, Taierhchuang is a village built by Taierhchuang and Hua. Taierhchuang has " four big families with canal opening" and is divided into four families: Yu, Tai, Hua and Huang, of which Tai and Hua lived earlier in Taierhchuang and were named after their surnames as "Taierhchuang" or "Taierhchuang". Before 1958, a stone tablet inscribed with "taijialin" was erected beside the grave outside the east gate of the former taierhchuang, and later generations of taijiaren came to worship it and was passed as a place of taijialing.
The surname village name of Taierhchuang not only exists for a long time but also changes constantly, mainly in the following three situations:

The first one is that the villagers who built the village at the beginning of the construction were first named after the surname of their clan and used the surname of the villagers from beginning to end. For example, "Guanzhuang (Pizhuang Town)" was renamed Guanzhuang after the official village because of Shangguan's surname. " Wu Zhai" Wu surname first lived here and was named Wu Jia Zhai, later changed to Wu Zhai.

The second is that there are two or more surnames in the village, among which the clan that holds the leading position in the village will name the village after the surname of its own clan. For example, " Li Jiazhuang" was originally named Dongfang, and it was renamed $\mathrm{Li}$ Jiazhuang because the majority of villagers are $\mathrm{Li}$. In the village of " Yang Zhang Zhuang", the villagers of Yang and Zhang Er are the majority, hence the name Yang Zhang Zhuang.

The third is that the village name of the original family name changed to the village name of the other family name due to the development and growth of the other family names. Society is always in constant development and change. Historical changes, economic development and population migration will lead to changes in the number of villagers and the proportion of surnames in villages, and such changes are uninterrupted. Influenced by these changes, the gradually growing family name will ban the dominant position of the original family name in the village, and in order to reflect the dominant position of the clan in the village, the village will be renamed with the family name of its own clan, such as "Hao Lou" formerly known as Peng He Village, where Peng originally lived. After the village Huo Xing prospered and built a building to live in, he changed his name to Huo Jia Lou. After the village Huo Xing Jue, Hao Xing moved in and Hao Xing Geng was named Hao Lou. "Sun Zhuang (Jiantou Town)" was originally named Wang Jiawan, the earliest village in wang xing, wang xing Jue, and Sun Geng's village was named Sun Jia Zhuang, or Sun Zhuang for short.

\section{PAY ATTENTION TO THE SOCIAL PSYCHOLOGICAL CULTURE OF THE ORIENTATION PATTERN}

In the place name system of our country, place names occupy a large proportion, which shows the importance people attach to each other.With the development of economy, the size and number of villages are constantly expanding, and the location word village name is gradually increasing in this case. Adding the location word to the original village name can not only help people accurately judge the location of the village, but also avoid the time-consuming and complicated trouble of renaming the village. Therefore, the location word village name is not only time-saving and labor-saving and easy to name, but also concise and easy to remember and conforms to the 
principles of simplicity and economy. About one-third of Taierhchuang's natural village names are bearing names, which account for a large proportion of the village names. These bearing village names represent their geographical positions with reference to geographical entities, such as "Shannan Tou" with reference to Montenegro, "Henghe Tou" with reference to Henghe, and "City, West" with reference to the ruins of the ancient city of Teyang, etc. Or take the original village as a reference and add the location words to express their geographical location. Such location words are often symmetrical to each other, such as East Xu Tang, West Xu Tang, Wan Dong, Wan Xi, Former Hexi, Later Hexi, Hou Meng Former, Hou Meng Later.

As a commonly used word, location words have been used for a long time and contain rich meanings. The location village names thus formed also have a strong cultural flavor. East, south, west and north are expressed in the same way all over the world as natural orientations, but in addition to expressing orientations in China, they also form a unique concept of orientation pattern. Chinese culture thinks that the east is opposite to the west, the east is better, the left is opposite to the right, and the left is the respect. The " east" is higher than the " west", " left" is higher than the "right", the east is opposite to the left, and the west is opposite to the right. For example, the "left king's room" is the " east king's room" in terms of orientation, and it is wang xing's village, formerly known as Wangzhuang, which was renamed Zuowangzhuang because the village was built in the east of Zuozhuang and later renamed Zuowangfang. The ancients also said that the most honored seat was " south" ( located in the north and facing south ), the ancients called the emperor " south", the emperor wanted to " listen to the world in the south" and the courtiers wanted to " do things in the north ( located in the south and facing north ).The same is true in the folk, where the upper position facing the south is reserved for the elders and venerates, while the lower position facing the north is occupied by the younger generation and subordinates. Over time, people's consciousness has formed the idea that the north is superior and the south is inferior, thus equating " north" with " upper" and " south" with " lower". For example, " upper chariot" is " north chariot" in terms of orientation, because the village is located to the north of the original red tile house chariot, hence its name. Opposite to the south and north are the front and the rear, facing the front in the south-central direction, and the north and the rear, such as "future" and " rear" formerly known as "future village" and "rear cheng village", where the cheng brothers set up villages and settled in the north and south, among which the one in the south is called future and the one in the north is called rear cheng. "Before the mountain" and "After the mountain" are named after the village stands in the south and north of the mountain.

\section{THE PURSUIT OF A BETTER LIFE OF SOCIAL PSYCHOLOGICAL CULTURE}

People always have special feelings for their place of residence, and vice versa. Some of Taierhchuang's natural village names express villagers' yearning for a better life. Some of these village names express their desire for peace, happiness and prosperity, such as Zhongwang Village, which is a place of prosperity for the villagers, is named Wangzhuang for its lucky image and is named Zhongwang Village because it lives in various villages. "Xin 'an" was named Xin 'an Zhuang because of the villagers' auspicious figure, and later evolved into Xin 'an. "Duolezhuang" was named Duolezhuang because it was proud of the fact that wang xing had fled the famine and settled in the village, cultivated the land and was self - sufficient. "Jidong, Jixi" was originally called Jizhuang. Later Huang changed the village name to Jili Village for Jili, later referred to as Jizhuang and divided into Jidong and Jixi. Some villages have a special geographical location when they were built, and the name was given at the beginning with an unlucky color. Later generations changed the village name because of taboo, such as "Shao Zhuang" which was named after Shao by the tomb, and "Tomb" which was renamed Shao Zhuang because of the unlucky character " Tomb". For example, " official animal husbandry" was originally named official tomb because it was established in front of the tomb and hence its name was changed to " official animal husbandry" because the word " tomb" was unlucky. Some village names show elegant aesthetic concepts. Some villages in Taierhchuang's natural village names are not good enough in content and elegant enough in words due to geographical conditions. In the process of using village names, people change village names to seek elegance and beauty. Most of these changes adopt the method of " homonym for righteousness" and retain or approach the original pronunciation in pronunciation, but change the vulgar and indecent meaning. For example, "Tuzhuang" was originally named Tujiazhuang, which was named after the village famous for its slaughter industry by Zhang and $\mathrm{Hu}$, and later renamed because of its indecency. "Langwo" was named after a wolf hole in front of Langshan because it was set up near Langshan, and later renamed because of the word "wolf". "Riverside Village" was named "Monk Village" because the village was built in a place called " Monk Forest", but it was renamed due to indecency. There are also some village names that express praise and worship for some people and things, such as "Desheng Village" was once a place of war between the Yuan and Ming armies, and the Ming army won a great victory. During the reign of Yongle in the Ming Dynasty, Du Muming built a village here and named it Desheng Village, which later evolved into Desheng Village. In short, these village names reflect people's pursuit of a better psychological state. 


\section{CONCLUSION}

The village name is a kind of language symbol system which is established by people and can reflect human ideology. It is closely related to people's life and is an important carrier of social psychological and cultural inheritance. This paper explores and analyzes the social, psychological and cultural connotation reflected in Taierhchuang village name from four aspects: attaching importance to religious belief, attaching importance to clan concept, attaching importance to the orientation pattern and pursuing a better life, highlighting the regional culture contained in Taierhchuang village name and providing reference materials for further analysis of Taierhchuang regional culture.

\section{REFERENCES}

[1] Local Records Compilation Committee, Taierhchuang District, Zaozhuang City, Shandong Province. Taierhchuang District Records [M]. Jinan: Shandong People's Publishing House, 1993.

[2] Zhao Yawei. Yi County Annals [M]. Beijing: Line Press, 2007.

[3] Li rulong. Chinese toponymy manuscript [m]. Shanghai: Shanghai education press, 1998.

[4] Wang Jitong. On Wang Jitong's Place Names [M]. Beijing: Social Science Literature Publishing House, 1999.

[5] Luo Changpei. Language and Culture [M]. Beijing: Beijing Press, 1996.

[6] Chen Wei. Taierhchuang [M]. Beijing: Zhonghua Book Company, 2012. 